acting whereas they did not. Another is that he had the legal power to use them, even to abuse them. Even when his diagnosis might have been close to the point, more often his treatments were not. For example, Charcot himself frequently treated hysteria by cauterization of the cervix uteri. Other surgical operations often used to treat hysteria included the entire gamut of gynaecological assaults, from clitoridectomy and ovariectomy to hysterectomy. Emil Kraepelin (1856-1926) criticized this type of therapy for hysteria as "knife happy". Charcot did not think of therapy as an experimental science.

He needed an audience but he kept it at a comfortable distance. This is depicted in Pierre André Brouillet's painting "A Clinical Lesson at the Salpêtrière" (1887), which is well discussed here. Charcot faces away from his admiring audience of mostly young men and looks past his half-naked patient. She is about to swoon into the arms of Babinski, whose compassion contrasts with Charcot's seeming indifference: an apparent lack of empathy that he seems to communicate to his audience. The picture can be interpreted as a study of exhibitionism and voyeurism. It is a lesson in medical ethics as much as in history.

Depictions of Charcot at work in his clinic have continued to bring up questions about medical ethics since they were first raised in the public press of Charcot's time. Is the professor's prestige possible only at the expense of his patients (and perhaps also his students)? Such questions form part of a continuing debate being fuelled by feminists as well as philosophers of science. Perhaps the initiation of that debate about the rights of the patient and the authority of the doctor may be seen to be Charcot's most enduring contribution. In that view, Charcot's legacy to our times is in relation to ethical consciousness rather than to positive scientific knowledge.

Marcus Jacobson is in the Department of Neurobiology and Anatomy, School of Medicine, University of Utah, Salt Lake City, Utah 84132, USA.

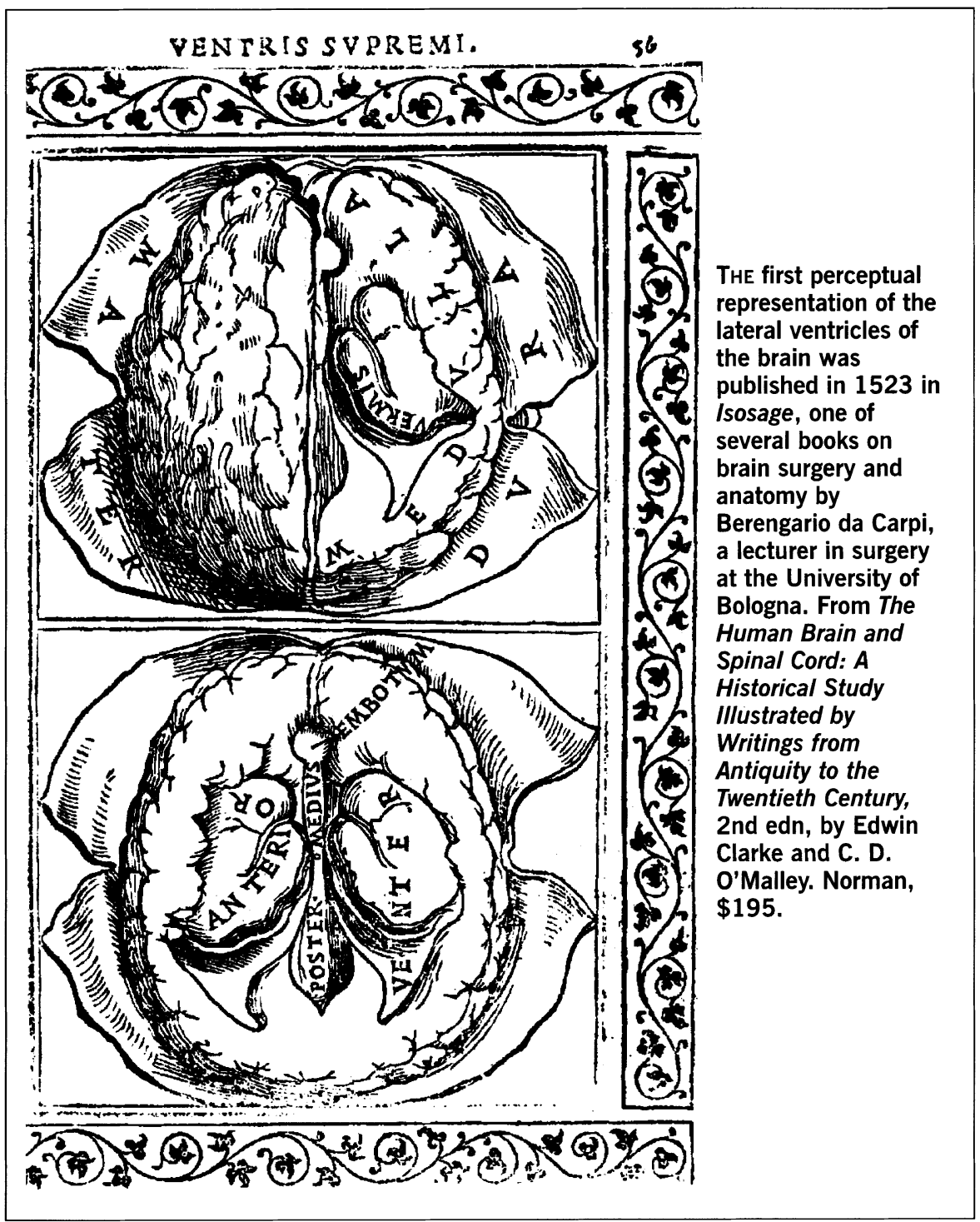

\section{Genes in mind}

\section{Kenneth S. Kendler}

Genetics and Mental IIIness: Evolving Issues for Research and Society. Edited by Laura Lee Hall. Plenum: 1996. Pp. 225. \$59.40, £39.60.

THREE powerful yet disparate recent trends in psychiatry and genetics are reflected in this unusual book: the emergence of a new conceptual approach to psychiatric genetics; the rise of mental health advocacy groups; and the burgeoning attention paid to the ethics of genetics research and practice.

Until the mid-1980s, research in psychiatric genetics was dominated by the traditional methods of family, twin and adoption studies, the goal of which was to quantify the familial aggregation of psychiatric disorders and to establish the extent to which such disorders were due to genetic as opposed to environmental factors. In these studies, genes were never directly measured. Rather, their action was inferred from the pattern of resemblance in relatives. By contrast, the past decade has seen an increasing focus on methods that attempt to pinpoint genes conferring susceptibility to psychiatric illness. This shift in emphasis has been driven by advances in molecular genetics in general and in methods of human gene mapping in particular. Although spectacularly successful for Mendelian genetic disorders, and increasingly applied to more complex conditions, these methods have yet to lead to major findings in the study of psychiatric illness. Recent studies hint at a linkage between certain gene markers and schizophrenia, bipolar affective illness and even personality, and may presage more definitive findings in the near future.

The second trend represented in this volume is the rise of consumer advocacy groups for mental health. Traditionally, the mentally ill have fared poorly in the rough and tumble of the political arena where, at least in the United States, decisions are usually made about the funding of both psychiatric research and clinical care for the mentally ill. This situation has, however, begun to change with the emergence of groups made up mostly of the mentally ill and their relatives. These advocacy groups have challenged, in direct and often effective ways, the prejudices with which society continues to view the mentally ill.

The third theme of this book is the ethics of research and practice in human genetics. With the support of funds from the Human Genome Project, the field has addressed a whole range of ethical issues. Few are more difficult than those 